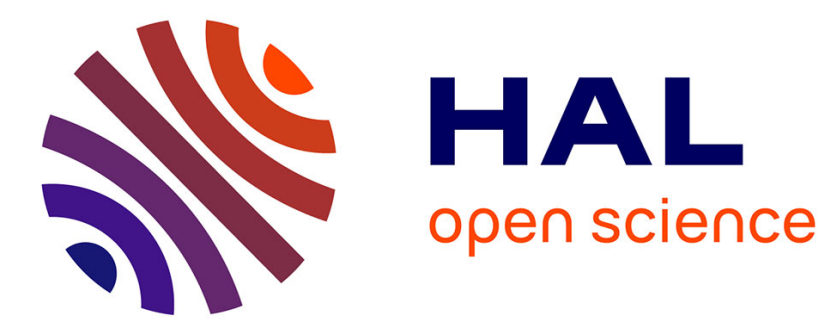

\title{
CALORIMETRY OF LIQUID CRYSTAL PHASE TRANSITIONS
}

\author{
D. Armitage, F. Price
}

\section{To cite this version:}

D. Armitage, F. Price. CALORIMETRY OF LIQUID CRYSTAL PHASE TRANSITIONS. Journal de Physique Colloques, 1975, 36 (C1), pp.C1-133-C1-136. 10.1051/jphyscol:1975125 . jpa-00215902

\section{HAL Id: jpa-00215902 https://hal.science/jpa-00215902}

Submitted on 1 Jan 1975

HAL is a multi-disciplinary open access archive for the deposit and dissemination of scientific research documents, whether they are published or not. The documents may come from teaching and research institutions in France or abroad, or from public or private research centers.
L'archive ouverte pluridisciplinaire HAL, est destinée au dépôt et à la diffusion de documents scientifiques de niveau recherche, publiés ou non, émanant des établissements d'enseignement et de recherche français ou étrangers, des laboratoires publics ou privés. 
Classification

Physics Abstracts

7.130

\title{
CALORIMETRY OF IIQUID CRYSTAL PHASE TRANSITIONS (*)
}

\author{
D. ARMITAGE and F. P. PRICE \\ Polymer Science and Engineering Department, University of Massachusetts \\ Amherst, Massachusetts 01002, USA
}

\begin{abstract}
Résumé. - Les transitions smectique-cholestérique ont été étudiées par DSC. Nous présentons des mesures calorimétriques relatives (1) au passage de la texture conique focale à celle de la phase bleue, (2) aux phénomènes prétransitionnels, et (3) à la surfusion.

Abstract. - The smectic and cholesteric phase transitions of cholesteryl myristate and cholesteryl nonanoate have been studied by differential scanning calorimetry. We report calorimetric observations related to (i) the focal-conic to blue phase transition (ii), pre-transition phenomena and (iii) supercooling.
\end{abstract}

1. Introduction. - Mesophase transitions show some of the character of both classical first and second order phase transitions. A measurement of any physical property through the transition region is of interest in a general theory of phase transition as well as in the theory of liquid crystals.

We present here some preliminary results of heat capacity of cholesteryl myristate (CM) and cholesteryl noanoate (CN) in the transition regions, using the Perkin-Elmer DSC 2. A second order like pretransition behavior is observable; also superheating and supercooling, which are the expected consequences of first order behavior, can be detected. In this paper we restrict our attention to the two cholesteryl esters, but it should be noted that our interpretation is influenced by similar measurements on the well-known nematogens PAA and MBBA.

It has long been known that on cooling into the cholesteric from the isotropic state that a clear, colored texture was obtained prior to the formation of the usual focal conic texture [1,2]. In CN and CM this texture is usually a bright blue although in the former it sometimes appears green [3, 4]. Friedel [2] identified this so called blue phase as merely a different texture of the same cholesteric state as was usually exemplified by the focal conic. More recent optical studies have indicated that the blue phase $\rightarrow$ focal conic transition is reversible $[3,4]$ even though no volume or heat change was detected in transversing the transition region. A textural change that is reversible with temperature is most remarkable. Accordingly when the tenfold increase in sensitivity in measurement of heat capacity and volume change become available to us in the instruments described below, we undertook a study to see if

(*) This research supported by Grant HL-13188 from the National Heart Lung Institute. we could detect enthalpy and volume differences between the blue phase and its corresponding focal conic texture.

2. Experimental. - The cholesteryl esters were obtained from the Eastman-Kodak Co., Rochester, New York and purified by recrystallization from n-pentanol two or three times [5].

Heat capacity was measured with the PerkinElmer DSC 2. The machine was run at the slowest speed, $0.31 \mathrm{deg} / \mathrm{min}$, so as to stay as close as possible to thermodynamic equilibrium, to get the best temperature resolution and to minimize the distortion introduced by machine time constants. Higher speeds can be used with advantage, when the heat capacity is not changing rapidly with temperature, to amplify the gradual changes as the transition is approached.

The samples weighing from 1 to $40 \mathrm{mg}$ were encapsulated in sealed aluminum cans. The DSC measurements were carried out in a nitrogen purge gas atmosphere.

Density measurements were made with a recording capillary dilatometer of our own design [6]. The sensitivity of this device is one part in $10^{6}$.

3. Results and discussion. - Figure 1 shows a DSC trace through the smectic and cholesteric transitions of CM. Here the horizontal axis is temperature, which is linearly programmed at $1.25 \mathrm{deg} / \mathrm{min}$, while the vertical axis is power. The curves are essentially identical for both increasing and decreasing temperature. By eliminating time from the two axes, one can regard the thermogram as a plot of heat capacity at constant pressure $\left(C_{\mathrm{p}}\right)$ as a function of temperature. However, in any detailed analysis, the kinetic nature of the experiment must be remembered. Short range fluctuations should be fast on the time scale of the experiment for 


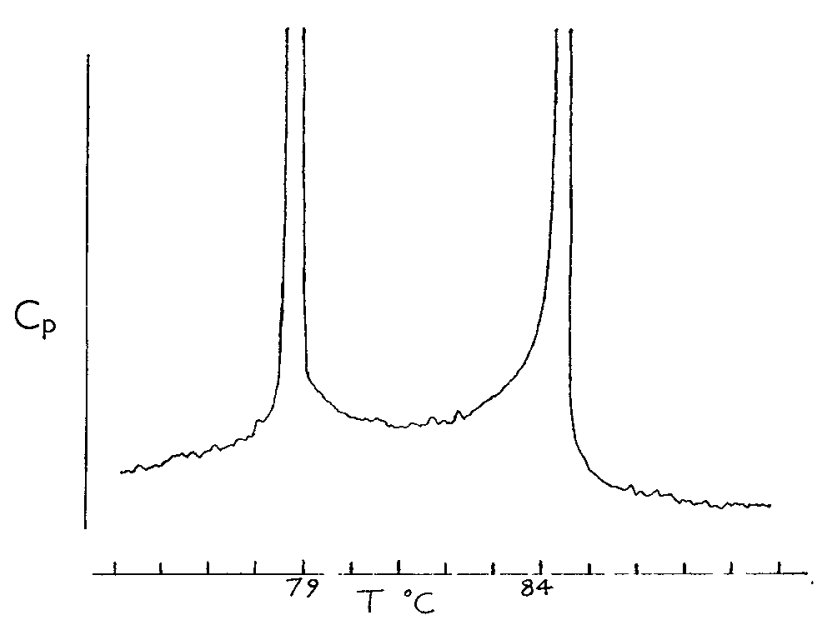

FIG. 1. - Thermogram showing smectic, cholesteric and isotropic regions of cholesteryl myristate. Temperature changing at $1.25 \mathrm{deg} / \mathrm{min}$.

distortion on this account to be insignificant. Long range reorganization of the material, through weak elastic forces could be slow, but this contribution to the heat capacity probably is small. A rise of $C_{\mathrm{p}}$ in anticipation of the transition, as shown here, is typical of liquid crystal transitions [7].

In order to look closely at the transition region, the machine is operated at the lowest speed, $0.31 \mathrm{deg} / \mathrm{min}$, resulting in figures 2 and 3 . The CM smectic to cholesteric transition is sharp compared with the cholesteric to isotropic transition; which suggests but does not prove that the broadening of the latter transition is not due to impurity. With rising temperature, the cholesteric to isotropic transition is preceded by a small peak about 0.5 degree below the main transition as shown in

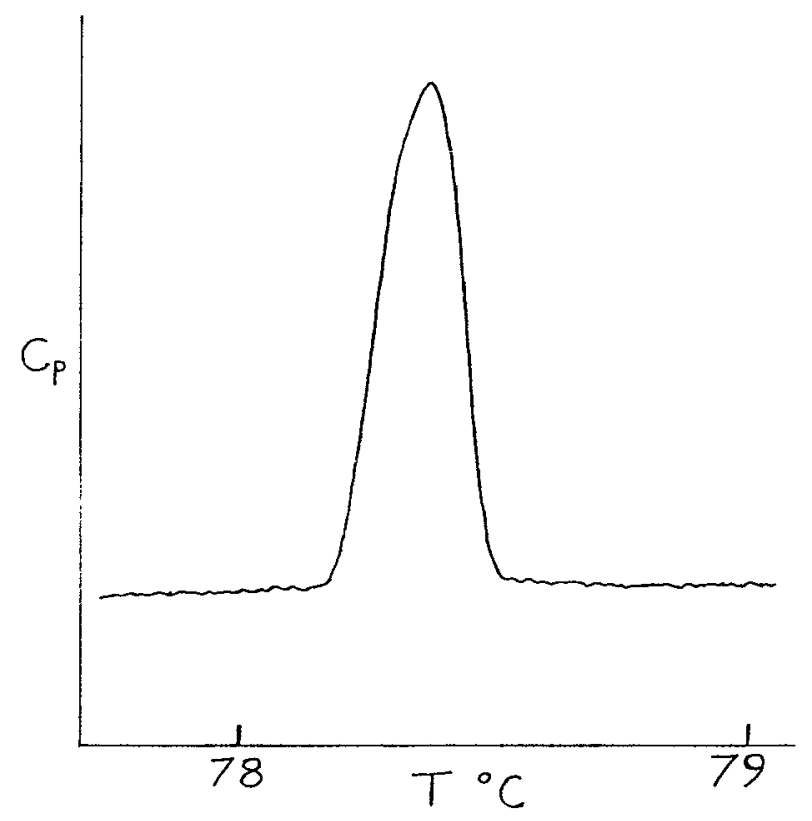

FIG. 2. - Smectic to cholesteric transition in cholesteryl myristate. Temperature increasing at $0.31 \mathrm{deg} / \mathrm{min}$.

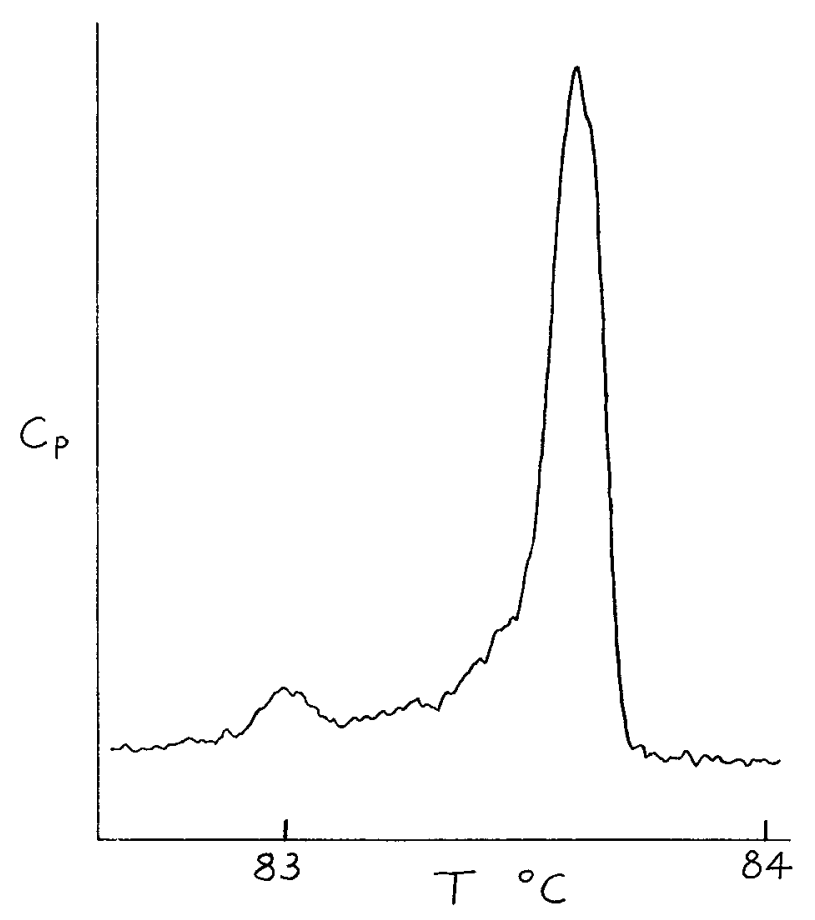

FIG. 3. - Cholesteric to isotropic transition in cholesteryl myristate. Temperature rising at $0.31 \mathrm{deg} / \mathrm{min}$.

figure 3. This small peak we associate with the transition cholesteric focal-conic to cholesteric blue phase. The effect is seen only with increasing temperature and not with decreasing temperature. Figure 4 shows the thermogram for decreasing temperature. Optical observations show the blue phase to focal-conic transition to be a slow nucleated transformation to the focal-conic texture [8]. This is in contrast to the sudden melting of the focal-conic texture on increasing the temperature into the blue phase $[3,4]$. This optically observed kinetic behavior is consistent with the DSC results.

The cholesteric to isotropic transition of $\mathrm{CN}$ is similar to $\mathrm{CM}$, again there is an additional small peak about 0.5 degree below the main transition, which we associate with the focal-conic to blue phase transition.

The CN smectic to cholesteric thermogram, figure 5, is surprisingly different from that for CM. On the cholesteric side, the approach to the transition is gradual, but from the smectic side the transition is sharp. In general shape it is the mirror image of the cholesteric to isotropic transition. It is interesting to note that irridescence is seen on the cholesteric side of the smectic transition in $\mathrm{CN}$, but not in the corresponding transition in $\mathrm{CM}^{3}$. A generalization (of only two cases) suggests that irridescence is associated with a gradual approach to the transition.

The sharpness of a transition, as measured by the DSC, is sensitive to superheating and supercooling. It is well known that when a superheated or supercooled phase starts to transform because of the sudden uptake or release of heat a jump in temperature approaching the amount of superheating or supercooling can take place at the onset of the phase transition. In response to 
the temperature jump, the DSC produces a power jump which is recorded on the output thermogram. Supercooling or superheating must enhance the sharpness of a transition, conversely the sharpness of a transition

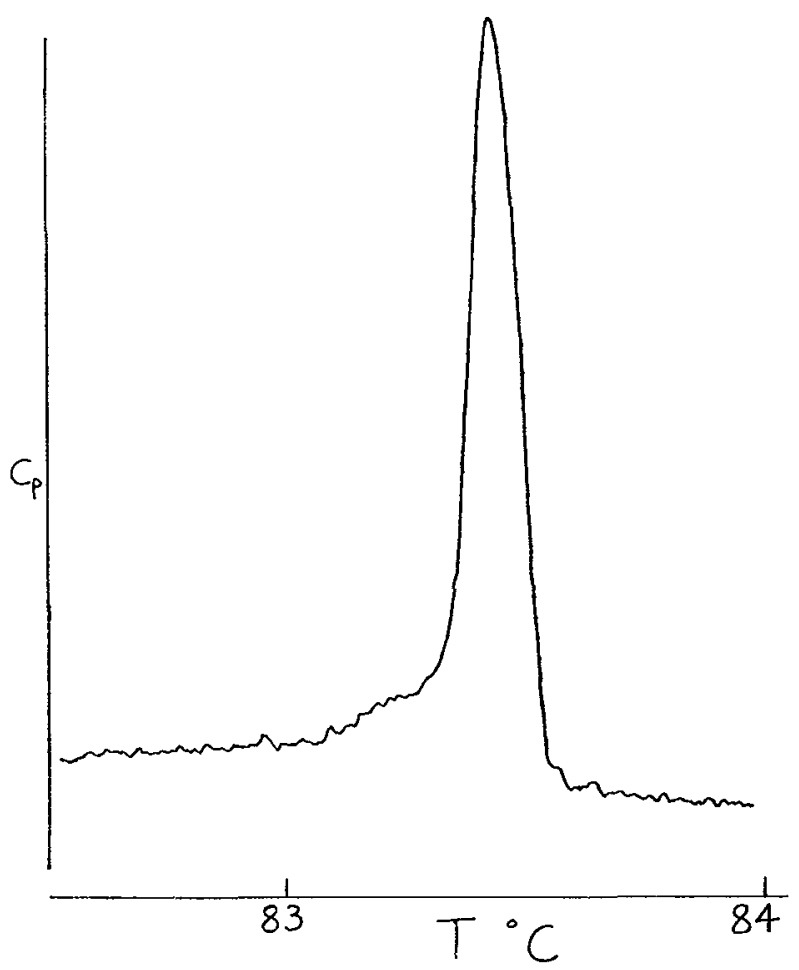

FIG. 4. - Isotropic to cholesteric transition in cholesteryl myristate. Temperature falling at $0.31 \mathrm{deg} / \mathrm{min}$.

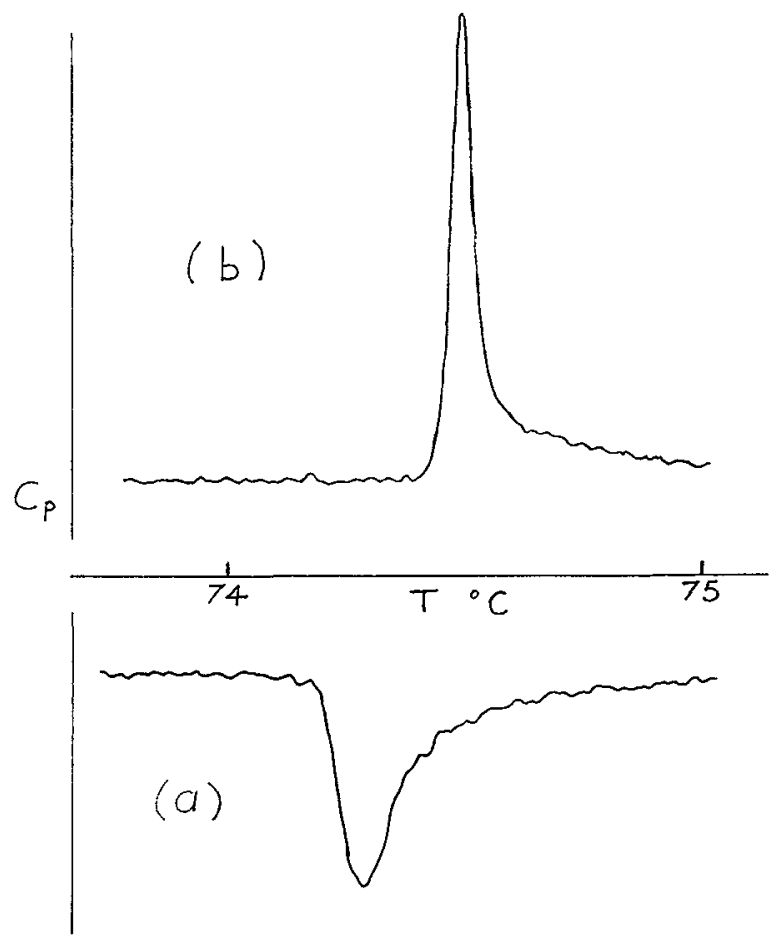

FIG. 5. - Exotherm (a) and endotherm (b) of smectic/cholesteric transition in cholesteryl nonanoate. Temperature changing at $0.31 \mathrm{deg} / \mathrm{min}$. can be indicative of supercooling or superheating. Further, comparison of the exotherm with the endotherm is indicative of the degree of supercooling relative to superheating. Generally the transition, liquid to solid crystal, is dominated by supercooling rather than superheating, e. g., we have compared the thermograms for the melting and crystallization of the pure metal indium. Here there is a five-fold increase in the height of the crystallization peak, compared with the melting peak, for a measured supercooling of 1.5 degree. The areas under the thermograms remain almost the same in the two cases, in accordance with well known thermodynamic arguments.

In transitions involving mesophases we observe in the DSC much smaller effects, suggesting a possible super/heating/cooling of 0.01 to 0.1 degree. The smaller supercooling is inferred from the shape of the thermogram rather than an actual temperature measurement. There are several factors which contribute to the shape of the thermogram, such as, thermal conductivity and specific heat at the transition temperature (where one expects anomalous behavior), temperature gradients, and machine distortions. Bearing this in mind, one must be very cautious when interpreting small changes in the thermogram as supercooling of order 0.01 degree. However, there is an independent assertion of supercooling in the PAA isotropic to nematic transition of order 0.01 degree [9].

All the isotropic to mesophase transitions have an exothermic peak which is higher than the endothermic peak, implying a dominant supercooling behavior, but only of order 0.01 degree. The thermograms of smectic to cholesteric transition in $\mathrm{CM}$ are virtually the same for exotherm and endotherm, implying an equal amount of superheating and supercooling (which could in this case be zero). The smectic to cholesteric transition in $\mathrm{CN}$ has a higher endotherm than exotherm, implying superheating rather than supercooling; also here we have a measurable difference in transition temperature of order 0.1 degree.

The density measurements reveal that a small change in density takes place at the onset of the blue phase. A positive identification can be made in this case, since the dilatometer permits optical observation of the sample during the density measurement. This result should be treated with some caution, since we have measurements for only one sample of $\mathrm{CN}$, and although the cholesteric to isotropic transition is high $\left(92.5^{\circ} \mathrm{C}\right)$ the smectic transition at $72^{\circ} \mathrm{C}$ is $2^{\circ} \mathrm{C}$ lower than the typical figure, which may indicate impurity.

4. Conclusion. - We have observed a heat of transition and density change at the focal-conic to blue phase transition, which is of order $1 \%$ of the transition blue phase to isotropic. A similar effect is reported by Arnold [10] for several cholesteric esters, although he does not specifically identify the effect with the transition to the blue phase.

This is a very weak effect and the sluggish kinetics 
make it unlikely that there is any change on a molecular scale. The significance of disclinations and possibly elastic energy in DSC measurements of the nematic to smectic transition in CBOOA has been reported [11]. A contribution of this nature would be significant in the very weak blue phase transition. In what follows we will denote as crystallites small domains of cholesteric order. One can be reasonably confident that the focalconic to blue phase transition involves a change in crystallite size by at least an order of magnitude. This follows from the lack of birefringence in the blue phase, presumably because the crystallite size changes from large to small compared with optical wavelengths. The elastic energy and disorder produced by this change in crystallite size may well account for the observed heat and density changes. It is difficult to find a physical explanation for a spontaneous reduction in crystallite size. A dynamic instability provoked by increasing amplitude of undulatory modes may be worth exploring.

The gradual approach to the isotropic transition from the blue phase, may also be a consequence of the small crystallite size, so that a range of sizes would produce a gradual transition.

A small supercooling of the transitions is not unexpected, and it is possible to interpret the isotropic to mesophase transitions in this way ; but the smallness of the effect here observed makes the result uncertain.

What we have interpreted as superheating in $\mathrm{CN}$ is unexpected. This is a near second order transition, with heat of transition less than $0.15 \mathrm{cal} / \mathrm{grm}$, which is about a quarter that of the corresponding CM transition. Yet the superheating effect is much larger in $\mathrm{CN}$. It is interesting to note that a hysteresis rather than supercooling effect has been noted [12] in the $\mathrm{CN}$ smectic transition; where it is attributed to the remnants of a cholesteric twist which persists into the smectic phase for a short time. As discussed previously, crystallite size could have some influence on this behavior.

Acknowledgments. - The authors are pleased to acknowledge helpful discussions with Prof. R. S. Porter and Prof. R. S. Stein during the course of this study.

\section{References}

[1] Lehmann, O., Flussige Kristalle, W. Engelmann (Leipzig) 1904.

[2] Friedel, G., Ann. Phys. 18 (1922) 274.

[3] Price, F. P. and Wendorff, J. H., J. Phys. Chem. 76 $276 \mathrm{C} 19$.

[4] GoldBerg, L. S. and SchnuUR, J. M., Radio and Electronic Engineer 39 (1970) 279.

[5] Davis, G. J. and Porter, R. S., Mol. Cryst. Liqu. Cryst. 6 (1970) 377.

[6] Detailed paper on the recording dilatometer will be published soon.
[7] Barral, E. M., Porter, R. S. and Johnson, J. F., J. Phys. Chem. 71 (1967) 895.

[8] Jabarin, A. and Stein, R. S., J. Phys. Chem. 77 (1972) 399 and 409.

[9] Ostner, W., Chan, S. K. and Kahlweit, M., 5th Int. Liquid Crystal Conf., Stockholm 1974.

[10] Jones, F. and Gruler, H., 5th Int. Liquid Crystal Conf., Stockholm 1974; J. Physique Colloq. 36 (1975) C1-53.

[11] Arnold, H. and Roediger, P., Z. Phys. Chem. (Leipzig) 239 (1968) 283.

[12] MCMillan, W. L., Phys. Rev. A 6 (1972) 936. 